\title{
Application of MCDM Approach-TOPSIS for the Multi-Objective Optimization Problem
}

\author{
Ch. Maheswara Rao ${ }^{1}$ and K. Venkatasubbaiah ${ }^{2}$ \\ ${ }^{1}$ Assistant Professor, Department of Mechanical Engineering, Raghu Institute of \\ Technology, Visakhapatnam, India \\ ${ }^{2}$ Professor, Department of Mechanical Engineering, Andhra University, \\ Visakhapatnam, Indi \\ mahe.mech129@gmail.com
}

\begin{abstract}
In the present work, an investigation has been made to study the effect of cutting parameters (speed, feed and depth of cut) on the multi-responses, Material Removal Rate $(M R R)$ and Surface Roughness $\left(R_{a}\right)$. The experiments were done on a conventional lathe using a tungsten carbide tool under dry environment. Twenty seven alternative combinations of speed, feed and depth of cut were considered (as per Taguchi's standard L27 Orthogonal Array) for the machining of medium carbon steel EN8. For the optimization of multi-responses, the Multi-criteria decision making (MCDM) method, TOPSIS has been employed. Main effect plot for the Signal-to-Noise (S/N) ratios of the relative closeness coefficient $\left(C_{i}^{+}\right)$was drawn using the MINITAB-16 software. From the TOPSIS and the main effect plot drawn for the relative closeness coefficient $\left(C_{i}^{+}\right)$, the optimal combination of the multi-responses were found at $27^{\text {th }}$ alternative i.e. speed at $760 \mathrm{rpm}$, feed at $0.3 \mathrm{~mm} / \mathrm{rev}$ and depth of cut at $1.5 \mathrm{~mm}$ respectively. The analysis of variance (ANOVA) has been done to know the influence of cutting parameters on the multi-responses. From the ANOVA results of the relative closeness coefficient $\left(C_{i}^{+}\right)$, it is found that the feed has high influence $(F=41.08)$ followed by the depth of cut $(F=25.78)$ and speed $(F=22.55)$.
\end{abstract}

Keywords: Material Removal Rate (MRR), Surface Roughness $\left(R_{a}\right)$, Relative Closeness Coefficient $\left(\mathrm{C}_{i}^{+}\right)$, TOPSIS and ANOVA

\section{Introduction}

Multi-criteria decision making (MCDM) is regarded as a main part of modern decision science and operational research, which contains multiple decision criteria and multiple decision alternatives. The objective of the MCDM is to find the most desirable alternative from a set of available alternatives versus the selected criteria. [1-6] Technique for order preference by similarity to an ideal solution (TOPSIS) is one of the well-known classical MCDM methods proposed by Hwang and Yoon for solving the decision making problems. It is based on the concepts that the chosen alternative should have the shortest distance from the positive ideal point and the farthest distance from the negative ideal point concurrently. The TOPSIS method first converts the various criteria, dimensions into non-dimensional criteria. Generally $\mathrm{A}^{+}$indicates the most preferable alternative or the ideal solution and $\mathrm{A}^{-}$indicates the least preferable alternative or the negative ideal solution. [7-12] The relative importance or weight of a criterion indicates the priority assigned to the criterion by the decision-maker while ranking the alternatives in a Multi criteria Decision-Making (MCDM) environment. The Entropy Method estimates the weights of the various criteria from the given payoff matrix and is independent of the views of the decision-maker. The weights of the criteria's depend on the amount of information available and its relationship with the importance of the criterion. If the 
entropy value is high, the uncertainty contained in the criterion vector is high, diversification of the information is low and correspondingly the criterion is less important. [13-14]

The productivity and surface quality are depends on the rate of material removed and the surface roughness. Surface roughness affects the functional attributes of parts such as, contact causing surface friction, wearing, light reflection, ability of distributing and holding a lubricant, load bearing capacity, coating and resisting fatigue. Generally the Material removal rate and Surface finish depend on various factors like cutting conditions (speed, feed and depth of cut), Work piece variables (hardness, mechanical and physical properties of the material) and tool variables (nose radius, rake angle, cutting edge geometry, tool vibrations, tool overhang, tool point angle etc.,). [15-17] For optimization of responses Taguchi has suggested a new design called robust design and uses orthogonal array (OA). An OA is a small set of all possibilities which help to determine the least number of alternatives, which will further help to conduct experiments to determine the optimum level for each process parameters and establish the relative importance of individual process parameters. [18-19]

For the present study, medium carbon steel EN8 have been chosen as the work piece. EN8 is medium carbon steel has high industrial applications in tool, oil and gas industries. It is most commonly used for axial shafts, propeller shafts, crank shafts, high tensile bolts and studs, connecting rods, riffle barrels and gears manufacturing, etc., A series of experiments were conducted on a conventional lathe by taking twenty seven (L27 OA) alternative conditions of speed, feed and depth of cut and the Material removal rate and Surface roughness as criteria's. [20-21] The multiple-responses were optimized using Multi-dimensional decision making (MCDM) method of TOPSIS. To know the effect of the cutting parameters on the Relative closeness coefficient $\left(\mathrm{C}_{\mathrm{i}}^{+}\right)$, Main effect plots for $\mathrm{C}_{\mathrm{i}}^{+}$ were drawn using the MINITAB-16 software. Also, Analysis of Variance (ANOVA) has been conducted to find the influence of cutting parameters [22-23] on the Relative closeness coefficient $\left(\mathrm{C}_{\mathrm{i}}^{+}\right)$.

\section{Experimental Details}

For the experimentation, a medium carbon steel EN8 having dimensions of $36 \mathrm{~mm}$ in diameter and $300 \mathrm{~mm}$ of length have been taken. The experiments were conducted on a conventional lathe having specifications of spindle speed $875 \mathrm{rpm}$ and maximum power of $0.75 \mathrm{KW}$ using a tungsten carbide tool under dry environment. The experiments were done as per the taguchi's standard L27 Orthogonal Array by considering the twenty seven alternatives of cutting parameters speed, feed and depth of cut. L27 OA with the actual cutting parameters was given in the Table 1 . After machining the surface roughness values of alternatives were measured with talysurf tester.

Table 1. Experimental Alternatives

\begin{tabular}{|c|c|c|c|}
\hline $\begin{array}{c}\text { Run No. } \\
\text { (Alternatives) }\end{array}$ & Speed (v) & Feed (f) & Depth of Cut (d) \\
\hline A-1 & 360 & 0.1 & 0.5 \\
\hline A-2 & 360 & 0.1 & 1 \\
\hline A-3 & 360 & 0.1 & 0.5 \\
\hline A-4 & 360 & 0.2 & 1 \\
\hline A-5 & 360 & 0.2 & 1.5 \\
\hline A-6 & 360 & 0.2 & \\
\hline
\end{tabular}




\begin{tabular}{|c|c|c|c|}
\hline A-7 & 360 & 0.3 & 0.5 \\
\hline A-8 & 360 & 0.3 & 1 \\
\hline A-9 & 360 & 0.3 & 1.5 \\
\hline A-10 & 560 & 0.1 & 0.5 \\
\hline A-11 & 560 & 0.1 & 1 \\
\hline A-12 & 560 & 0.1 & 1.5 \\
\hline A-13 & 560 & 0.2 & 0.5 \\
\hline A-14 & 560 & 0.2 & 1 \\
\hline A-15 & 560 & 0.2 & 1.5 \\
\hline A-16 & 560 & 0.3 & 0.5 \\
\hline A-17 & 560 & 0.3 & 1 \\
\hline A-18 & 560 & 0.3 & 1.5 \\
\hline A-19 & 760 & 0.1 & 0.5 \\
\hline A-20 & 760 & 0.1 & 1 \\
\hline A-21 & 760 & 0.1 & 1.5 \\
\hline A-22 & 760 & 0.2 & 0.5 \\
\hline A-23 & 760 & 0.2 & 1 \\
\hline A-24 & 760 & 0.2 & 1.5 \\
\hline A-25 & 760 & 0.3 & 0.5 \\
\hline A-26 & 760 & 0.3 & 1 \\
\hline A-27 & 760 & 0.3 & 1.5 \\
\hline
\end{tabular}

\section{Methodology}

TOPSIS decision making method is a technique introduced by Yoon and Hwang. It is a worldwide accepted approach to finding the best alternative that is closest to the ideal solution.

TOPSIS procedural steps

- Determination of weights $\left(\mathrm{W}_{\mathrm{j}}\right)$ using an entropy approach

- Determination of the Normalized decision making matrix $\left(\mathrm{r}_{\mathrm{ij}}\right)$

- Construction of a weighted normalized decision matrix $\left(\mathrm{V}_{\mathrm{ij}}\right)$

- Determination of Positive ideal solution (PIS) and Negative ideal solutions (NIS)

- Determination of the separation values from the PIS and NIS

- Determination of the relative closeness to the ideal solutions and corresponding Signal to noise $(\mathrm{S} / \mathrm{N})$ ratios 
- $\quad$ Rank the alternatives in descending order of relative closeness coefficient $\left(\mathrm{C}_{\mathrm{i}}^{+}\right)$.

Step 1: Determination of weights using entropy approach

The entropy approach includes in four steps they are,
i. Formation of a decision matrix (D)
ii. Formation of Normalized decision matrix
iii. Calculation of output entropy $\left(\dot{\varepsilon}_{\mathrm{j}}\right)$
iv. Calculation of the weight $\left(\mathrm{W}_{\mathrm{j}}\right)$

(i). Formation of a decision matrix (D)

In a decision matrix, the rows are assigned to available alternatives and the columns are assigned to characteristics. The general decision matrix can be shown as

$$
\mathrm{D}=\underset{A_{\mathrm{i}}}{A_{\mathrm{m}}}\left[\begin{array}{ccccc}
\mathrm{Y}_{11} & \mathrm{Y}_{12} & \ldots & \mathrm{Y}_{1 \mathrm{j}} & \mathrm{Y}_{1 \mathrm{n}} \\
\mathrm{Y}_{\mathrm{m} 1} & \mathrm{Y}_{\mathrm{i} 2} & \ldots & \mathrm{Y}_{\mathrm{ij}} & \ldots \\
\mathrm{Y}_{\mathrm{m} 1} & \mathrm{Y}_{\mathrm{m} 2} & \ldots & \mathrm{Y}_{\mathrm{mj}} & \mathrm{Y}_{\mathrm{mn}}
\end{array}\right]
$$

Where, $A_{i}(i=1,2,3 \ldots \ldots . . m)$ signifies the potential alternatives, $Y_{j}(J=1,2,3 \ldots \ldots . . n)$ signifies the attributes and $Y_{i j}$ is the performance of $A_{i}$ with respect to characteristic $Y_{j}$.

(ii). Formation of Normalized decision matrix $\left(\overline{\boldsymbol{Y}}_{i j}\right)$

$\bar{Y}_{\mathrm{ij}}=\frac{\mathrm{Y}_{\mathrm{ij}}}{\sum_{\mathrm{i}=1}^{\mathrm{m}} \mathrm{Y}_{\mathrm{ij}}} \quad(1 \leq \mathrm{i} \leq \mathrm{m}, 1 \leq \mathrm{j} \leq \mathrm{n})$

(iii). Calculation of output entropy $\left(\dot{\varepsilon}_{\mathrm{j}}\right)$

$$
\dot{\varepsilon}_{\mathrm{j}}=\frac{-1}{\ln (\mathrm{m})} \sum_{\mathrm{i}=1}^{\mathrm{m}} \overline{\mathrm{Y}}_{\mathrm{ij}} \ln \overline{\mathrm{Y}}_{\mathrm{ij}}
$$

(iv). Calculation of the weight $\left(\mathrm{W}_{\mathrm{j}}\right)$

$$
W_{j}=\frac{1-\hat{\varepsilon}_{j}}{\sum_{i=1}^{m}\left(1-\hat{\varepsilon}_{j}\right)}
$$

Where, $\sum_{\mathrm{i}=1}^{\mathrm{m}} \mathrm{W}_{\mathrm{j}}=1$ and $\left(1-\varepsilon_{\mathrm{j}}\right)$ is called uncertainty.

Step 2. Determination of the Normalized decision making matrix $\left(\mathrm{r}_{\mathrm{ij}}\right)$

Normalize the decision matrix of $\mathrm{r}_{\mathrm{ij}}$ can be determined by using

$$
\text { rij }=\frac{\mathrm{Y}_{\mathrm{ij}}}{\sqrt{\sum_{\mathrm{i}=1}^{\mathrm{n}} \mathrm{Y}_{\mathrm{ij}}{ }^{\mathrm{z}}}}
$$

Where, $r_{i j}$ represents the normalized performance of $A_{i}$ with respect to characteristic $Y_{j}$.

Step 3. Construction of a weighted normalized decision matrix $\left(\mathrm{V}_{\mathrm{ij}}\right)$

$$
V_{i j}=W_{j} r_{i j}
$$

Where, $\mathrm{W}_{\mathrm{j}}$ represents the relative weight of the $\mathrm{J}^{\text {th }}$ criteria.

Step 4. Determination of Positive ideal solution (PIS) and Negative ideal solutions (NIS)

$$
\text { Positive ideal solution, } \left.A^{+}=\left\{\left(\max _{1} V_{1 j} \mid j \varepsilon J\right),\left(\operatorname{minV}_{1 \jmath} \mid j \varepsilon J\right)_{1}=1,2 \ldots m\right)\right\}
$$




$$
\begin{aligned}
&=\left\{v_{1}^{+}, v_{2}^{+}, \ldots \ldots v_{j}^{+}, \ldots \ldots v_{n}^{+}\right\} \\
& \text {Negative ideal solution, } \mathrm{A}^{-}=\left\{\left(\operatorname{mm}_{1} \mathrm{~V}_{1 \mathrm{j}} \| \mathrm{J} \varepsilon \mathrm{J}\right),\left(\max \mathrm{V}_{1 \mathrm{j}} \mid \mathrm{J} \varepsilon \mathrm{J}\right)_{1}=1,2, \ldots \ldots \mathrm{m}\right\} \\
&=\left\{v_{1}^{-}, v_{2}^{-}, \ldots \ldots v_{j}^{-}, \ldots \ldots v_{n}^{-}\right\}
\end{aligned}
$$

$\mathrm{J}=1,2,3 \ldots \ldots . . \mathrm{n}$, associated with the beneficial attributes.

$\mathrm{J}=1,2,3 \ldots \mathrm{n}$, associated with non-beneficial adverse attributes.

Step 5. Determination of the separation values from the PIS and NIS

The separation of each alternative from PIS is given by $S_{i}^{+}=\sqrt{\sum_{j=1}^{n}\left(v_{i}^{+}-v_{i j}\right)^{2}}$; Where, $i$ $=1,2 \ldots \mathrm{m}$.

The separation of each alternative from NIS is given by $S_{i}^{-}=\sqrt{\sum_{j=1}^{n}\left(v_{j}^{-}-v_{i j}\right)^{2}}$; Where, $i$ $=1,2 \ldots \mathrm{m}$.

Step 6. Determination of the relative closeness to the ideal solutions and corresponding Signal to noise $(\mathrm{S} / \mathrm{N})$ ratios

$$
\text { Relative closeness coefficient }\left(\mathrm{C}_{\mathrm{i}}^{+}\right)=\mathrm{S}_{\mathrm{i}}^{-} /\left(\mathrm{S}_{\mathrm{i}}^{+}+\mathrm{S}_{\mathrm{i}}^{-}\right) \text {Where } \mathrm{i}=1,2 \ldots \ldots \mathrm{m}
$$

The larger the $\mathrm{C}_{\mathrm{i}}^{+}$value, the better the performance of the alternatives. The corresponding $\mathrm{S} / \mathrm{N}$ ratios of $\mathrm{C}_{\mathrm{i}}^{+}$were calculated from Taguchi's Larger-the-Better characteristic.

Step 7. Rank the alternatives in descending order of $\mathrm{C}_{\mathrm{i}}^{+}$

\section{Results and Discussions}

The experiments were conducted for twenty seven alternatives (L27 OA) of speed, feed and depth of cut and the criterion values obtained were given in the Table 2. Optimization of multi-responses using TOPSIS have been discussed below. 
Table 2. Experimental Results

\begin{tabular}{|c|c|c|}
\hline \multirow{2}{*}{$\begin{array}{c}\text { Run No. } \\
\text { (Alternatives) }\end{array}$} & \multicolumn{2}{|c|}{ Criteria } \\
\hline & MRR & $\mathrm{R}_{\mathrm{a}}$ \\
\hline A-1 & 11.38 & 5.0 \\
\hline A-2 & 21.75 & 5.7 \\
\hline A-3 & 31.39 & 4.7 \\
\hline A-4 & 20.74 & 5.6 \\
\hline A-5 & 38.66 & 6.2 \\
\hline A-6 & 53.01 & 7.2 \\
\hline A-7 & 39.38 & 9.4 \\
\hline A-8 & 69.72 & 8.9 \\
\hline A-9 & 100.02 & 5.5 \\
\hline A-10 & 13.7 & 5.0 \\
\hline A-11 & 24.3 & 5.3 \\
\hline A-12 & 34.71 & 3.8 \\
\hline A-13 & 13.98 & 5.3 \\
\hline A-14 & 25.8 & 4.4 \\
\hline A-15 & 36.25 & 6.9 \\
\hline A-16 & 46.12 & 9.2 \\
\hline A-17 & 78.50 & 7.0 \\
\hline A-18 & 92.03 & 4.4 \\
\hline A-19 & 25.52 & 2.5 \\
\hline A-20 & 46.32 & 3.7 \\
\hline A-21 & 66.26 & 7.4 \\
\hline A-22 & 42.86 & 5.1 \\
\hline A-23 & 78.53 & 4.0 \\
\hline A-24 & 102.46 & 6.7 \\
\hline A-25 & 63.72 & 8.0 \\
\hline A-26 & 117.80 & 6.9 \\
\hline A-27 & 119.60 & 3.5 \\
\hline
\end{tabular}


Step 1. Calculation of weights of the criteria using Entropy method.

The normalized values of criteria's were given in the Table 3 .

Table 3. Normalized Values of Criteria

\begin{tabular}{|c|c|c|}
\hline Run No. & MRR & $\mathrm{R}_{\mathrm{a}}$ \\
\hline A-1 & 0.00805 & 0.03179 \\
\hline A-2 & 0.01538 & 0.03624 \\
\hline A-3 & 0.02219 & 0.02988 \\
\hline A-4 & 0.01466 & 0.03560 \\
\hline A-5 & 0.02733 & 0.03942 \\
\hline A-6 & 0.03748 & 0.04577 \\
\hline A-7 & 0.02784 & 0.05976 \\
\hline A-8 & 0.04929 & 0.05658 \\
\hline A-9 & 0.07071 & 0.03497 \\
\hline A-10 & 0.00969 & 0.03179 \\
\hline A-11 & 0.01718 & 0.03369 \\
\hline A-12 & 0.02454 & 0.02416 \\
\hline A-13 & 0.00988 & 0.03369 \\
\hline A-14 & 0.01824 & 0.02797 \\
\hline A-15 & 0.02563 & 0.04387 \\
\hline A-16 & 0.03260 & 0.05849 \\
\hline A-17 & 0.05550 & 0.04450 \\
\hline A-18 & 0.06506 & 0.02797 \\
\hline A-19 & 0.01804 & 0.01589 \\
\hline A-20 & 0.03275 & 0.02352 \\
\hline A-21 & 0.04684 & 0.04704 \\
\hline A-22 & 0.03030 & 0.03242 \\
\hline A-23 & 0.05552 & 0.02543 \\
\hline A-24 & 0.07243 & 0.04259 \\
\hline A-25 & 0.04505 & 0.05086 \\
\hline A-26 & 0.08328 & 0.04387 \\
\hline A-27 & 0.08455 & 0.02225 \\
\hline
\end{tabular}


The output entropy and weight values for the criteria's were calculated and given in the Tables 4, and 5 .

Table 4. Output Entropy Values

\begin{tabular}{|c|c|c|}
\hline Criteria & MRR & $\mathrm{R}_{\mathrm{a}}$ \\
\hline$\dot{\varepsilon}_{\mathrm{j}}$ & 0.94491 & 0.98614 \\
\hline
\end{tabular}

Table 5. Weights of Criteria's

\begin{tabular}{|c|c|c|}
\hline Criteria & MRR & $\mathrm{R}_{\mathrm{a}}$ \\
\hline $\mathrm{W}_{\mathrm{j}}$ & 0.79897 & 0.20103 \\
\hline
\end{tabular}

Step 2. The calculated Normalized decision making matrix $\left(\mathrm{r}_{\mathrm{ij}}\right)$ values were given in the Table 6.

Table 6. Normalized Decision Matrix $\left(r_{i j}\right)$

\begin{tabular}{|c|c|c|}
\hline $\begin{array}{c}\text { Run No. } \\
\text { (Alternatives) }\end{array}$ & MRR & $\mathrm{R}_{\mathrm{a}}$ \\
\hline $\mathrm{A}-1$ & 0.03570 & 0.15811 \\
\hline A-2 & 0.06824 & 0.18024 \\
\hline A-3 & 0.09849 & 0.14862 \\
\hline A-4 & 0.06507 & 0.17708 \\
\hline A-5 & 0.12130 & 0.19605 \\
\hline A-6 & 0.16632 & 0.22767 \\
\hline A-7 & 0.12355 & 0.29724 \\
\hline A-8 & 0.21875 & 0.28143 \\
\hline A-9 & 0.31381 & 0.17392 \\
\hline A-10 & 0.04298 & 0.15811 \\
\hline A-11 & 0.07624 & 0.16759 \\
\hline A-12 & 0.10890 & 0.12016 \\
\hline A-13 & 0.04386 & 0.16759 \\
\hline A-14 & 0.08095 & 0.13913 \\
\hline A-15 & 0.11373 & 0.21819 \\
\hline A-16 & 0.14470 & 0.29092 \\
\hline A-17 & 0.24629 & 0.22135 \\
\hline A-18 & 0.28874 & 0.13913 \\
\hline A-19 & 0.08007 & 0.07905 \\
\hline A-20 & 0.14533 & 0.11700 \\
\hline
\end{tabular}




\begin{tabular}{|c|c|c|}
\hline A-21 & 0.20789 & 0.23400 \\
\hline A-22 & 0.13447 & 0.16127 \\
\hline A-23 & 0.24639 & 0.12649 \\
\hline A-24 & 0.32147 & 0.21186 \\
\hline A-25 & 0.19992 & 0.25297 \\
\hline A-26 & 0.36960 & 0.21819 \\
\hline A-27 & 0.37524 & 0.11068 \\
\hline
\end{tabular}

Step 3. The calculated weighted normalized decision matrix $\left(\mathrm{V}_{\mathrm{ij}}\right)$ values were given in the Table 7.

Table 7. Weighted Normalized Decision Matrix $\left(\mathrm{V}_{\mathrm{ij}}\right)$

\begin{tabular}{|c|c|c|}
\hline $\begin{array}{c}\text { Run No. } \\
\text { (Alternatives) }\end{array}$ & MRR & $\mathrm{R}_{\mathrm{a}}$ \\
\hline A-1 & 0.02853 & 0.03178 \\
\hline A-2 & 0.05452 & 0.03623 \\
\hline A-3 & 0.07869 & 0.02987 \\
\hline A-4 & 0.05199 & 0.03559 \\
\hline A-5 & 0.09692 & 0.03941 \\
\hline A-6 & 0.13289 & 0.04576 \\
\hline A-7 & 0.09872 & 0.05975 \\
\hline A-8 & 0.17478 & 0.05657 \\
\hline A-9 & 0.25074 & 0.03496 \\
\hline A-10 & 0.03434 & 0.03178 \\
\hline A-11 & 0.06092 & 0.03369 \\
\hline A-12 & 0.08701 & 0.02415 \\
\hline A-13 & 0.03505 & 0.03369 \\
\hline A-14 & 0.06468 & 0.02797 \\
\hline A-15 & 0.09087 & 0.04386 \\
\hline A-16 & 0.11562 & 0.05847 \\
\hline A-17 & 0.19679 & 0.04449 \\
\hline A-18 & 0.23071 & 0.02797 \\
\hline A-19 & 0.06398 & 0.01589 \\
\hline A-20 & 0.11612 & 0.02352 \\
\hline
\end{tabular}




\begin{tabular}{|c|c|c|}
\hline A-21 & 0.16610 & 0.04703 \\
\hline A-22 & 0.10744 & 0.03242 \\
\hline A-23 & 0.19686 & 0.02542 \\
\hline A-24 & 0.25685 & 0.04258 \\
\hline A-25 & 0.15974 & 0.05085 \\
\hline A-26 & 0.29531 & 0.04386 \\
\hline A-27 & 0.29982 & 0.02225 \\
\hline
\end{tabular}

Step 4. The calculated Positive ideal solution (PIS) and Negative ideal solutions (NIS) values were given in the Table 8 .

Table 8. PIS \& NIS Values

\begin{tabular}{|c|c|c|}
\hline Criteria & MRR & $\mathrm{R}_{\mathrm{a}}$ \\
\hline PIS & 0.29982 & 0.01589 \\
\hline NIS & 0.02853 & 0.05975 \\
\hline
\end{tabular}

Step 5. The calculated separation values from the PIS and NIS were given in the Table 9.

Table 9. Distance Measures

\begin{tabular}{|c|c|c|}
\hline $\begin{array}{c}\text { Run No. } \\
\text { (Alternatives) }\end{array}$ & $\mathrm{S}_{\mathrm{i}}^{+}$ & $\mathrm{S}_{\mathrm{i}}{ }^{-}$ \\
\hline A-1 & 0.27175 & 0.02793 \\
\hline A-2 & 0.24613 & 0.03501 \\
\hline A-3 & 0.22158 & 0.05836 \\
\hline A-4 & 0.24861 & 0.03362 \\
\hline A-5 & 0.20426 & 0.07132 \\
\hline A-6 & 0.16958 & 0.07019 \\
\hline A-7 & 0.20582 & 0.14628 \\
\hline A-8 & 0.13147 & 0.22357 \\
\hline A-9 & 0.05262 & 0.02853 \\
\hline A-10 & 0.26595 & 0.04158 \\
\hline A-11 & 0.23957 & 0.06849 \\
\hline A-12 & 0.21297 & 0.02688 \\
\hline A-13 & 0.26538 & 0.04813 \\
\hline A-14 & 0.23546 & \\
\hline
\end{tabular}




\begin{tabular}{|c|l|l|}
\hline A-15 & 0.21080 & 0.06432 \\
\hline A-16 & 0.18905 & 0.08709 \\
\hline A-17 & 0.10694 & 0.16894 \\
\hline A-18 & 0.07019 & 0.20466 \\
\hline A-19 & 0.23584 & 0.05636 \\
\hline A-20 & 0.18387 & 0.09477 \\
\hline A-21 & 0.13729 & 0.13815 \\
\hline A-22 & 0.19308 & 0.08353 \\
\hline A-23 & 0.10339 & 0.17354 \\
\hline A-24 & 0.05056 & 0.22896 \\
\hline A-25 & 0.14437 & 0.13151 \\
\hline A-26 & 0.02829 & 0.26725 \\
\hline A-27 & 0.00632 & 0.27388 \\
\hline
\end{tabular}

Step 6. The calculated relative closeness coefficient values $\left(\mathrm{C}_{\mathrm{i}}^{+}\right)$to the ideal solutions (PIS and NIS) and the corresponding Signal-to-Noise $(\mathrm{S} / \mathrm{N})$ ratios were given in the table 10. The ranking of alternatives was given in the descending order of $\mathrm{C}_{i}^{+}$values. A graph is drawn by taking the Experiment number on $\mathrm{X}$-axis and Relative Closeness Coefficient $\left(\mathrm{C}_{\mathrm{i}}^{+}\right)$values on the $\mathrm{Y}$-axis using EXCEL and shown in the figure 1. From the Figure 1, it is clear that the $\mathrm{C}_{\mathrm{i}}^{+}$value is high for the twenty seventh alternative.

Table 10. Relative Closeness Coefficient $\left(\mathrm{C}_{\mathrm{i}}^{+}\right)$

\begin{tabular}{|c|c|c|c|}
\hline $\begin{array}{c}\text { Run No. } \\
\text { (Alternatives) }\end{array}$ & $\mathrm{C}_{\mathrm{i}}^{+}$ & $\mathrm{S} / \mathrm{N} \mathrm{of} \mathrm{C}_{\mathrm{i}}^{+}$ & Rank \\
\hline $\mathrm{A}-1$ & 0.0932 & -20.6122 & 26 \\
\hline $\mathrm{A}-2$ & 0.1245 & -18.0946 & 23 \\
\hline $\mathrm{A}-3$ & 0.2085 & -13.6189 & 24 \\
\hline $\mathrm{A}-4$ & 0.1191 & -18.4796 & 15 \\
\hline $\mathrm{A}-5$ & 0.2588 & -11.7406 & 11 \\
\hline $\mathrm{A}-6$ & 0.3831 & -8.3335 & 16 \\
\hline $\mathrm{A}-7$ & 0.2543 & -11.8929 & 4 \\
\hline $\mathrm{A}-8$ & 0.5267 & -5.5694 & 25 \\
\hline A-9 & 0.8095 & -1.8360 & 22 \\
\hline A-10 & 0.0969 & -20.2757 & 17 \\
\hline A-11 & 0.1479 & -16.6011 & -12.2762 \\
\hline A-12 & 0.2433 & & \\
\hline
\end{tabular}




\begin{tabular}{|c|c|c|c|}
\hline A-13 & 0.0920 & -20.7272 & 27 \\
\hline A-14 & 0.1697 & -15.4054 & 18 \\
\hline A-15 & 0.2338 & -12.6239 & 13 \\
\hline A-16 & 0.3154 & -10.0235 & 7 \\
\hline A-17 & 0.6124 & -4.2596 & 20 \\
\hline A-18 & 0.7446 & -2.5613 & 12 \\
\hline A-19 & 0.1929 & -14.2944 & 9 \\
\hline A-20 & 0.3401 & -9.3672 & 6 \\
\hline A-21 & 0.5016 & -5.9935 & 3 \\
\hline A-22 & 0.3020 & -10.4003 & 10 \\
\hline A-23 & 0.6267 & -4.0595 & 2 \\
\hline A-24 & 0.8191 & -1.7330 & 1 \\
\hline A-25 & 0.4767 & -6.4352 & -0.8740 \\
\hline A-26 & 0.9043 & -0.1983 & \\
\hline A-27 & 0.9774 & & 2 \\
\hline
\end{tabular}

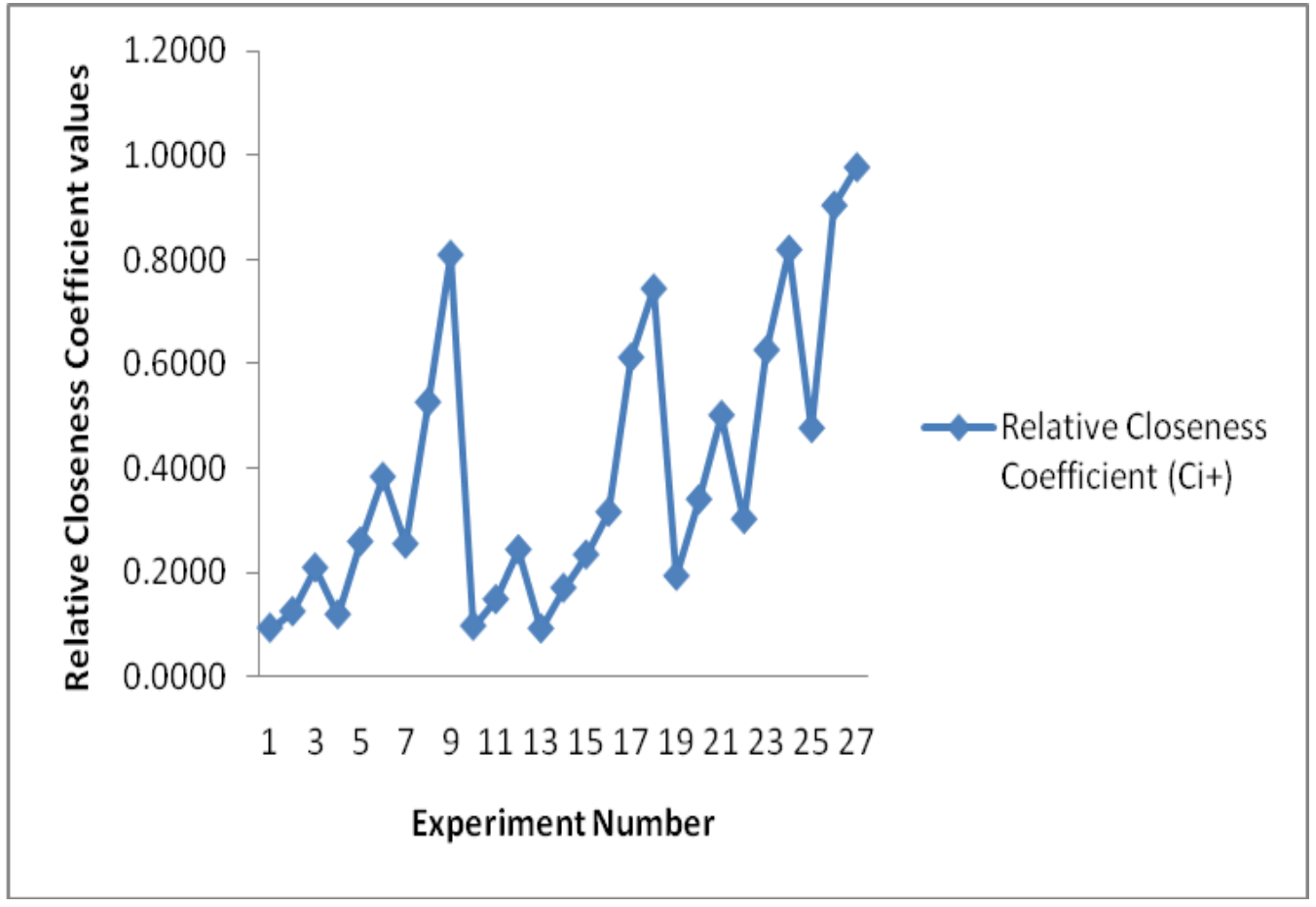

Figure 1. Experimental Number Vs. $C_{i}^{+}$

The response table for Signal-to-Noise $(\mathrm{S} / \mathrm{N})$ ratios of the Relative closeness coefficient $\left(\mathrm{C}_{\mathrm{i}}^{+}\right)$was given in the Table 11. Also the main effect plots were drawn for the Signal-to-Noise $(\mathrm{S} / \mathrm{N})$ ratios of the relative closeness coefficient $\left(\mathrm{C}_{\mathrm{i}}^{+}\right)$by using the 
MINITAB-16 software and shown in the Figures 2, and 3. In the main effect plot, the $\mathrm{X}$-axis represents the cutting parameters with their levels and the $\mathrm{Y}$-axis represents the response. From the Main effect plots, it is observed that the Relative closeness coefficient $\left(\mathrm{C}_{\mathrm{i}}^{+}\right)$is mainly effected due to feed, followed by depth of cut and speed respectively.

Table 11. Response Table for Signal-to-Noise Ratios

\begin{tabular}{|c|c|c|c|}
\hline Level & $\mathrm{v}$ & $\mathrm{f}$ & $\mathrm{d}$ \\
\hline 1 & -12.242 & -14.570 & -14.793 \\
\hline 2 & -12.750 & -11.500 & -9.552 \\
\hline 3 & -5.928 & -4.850 & -6.575 \\
\hline Delta & 6.822 & 9.720 & 8.219 \\
\hline Rank & 3 & 1 & 2 \\
\hline
\end{tabular}

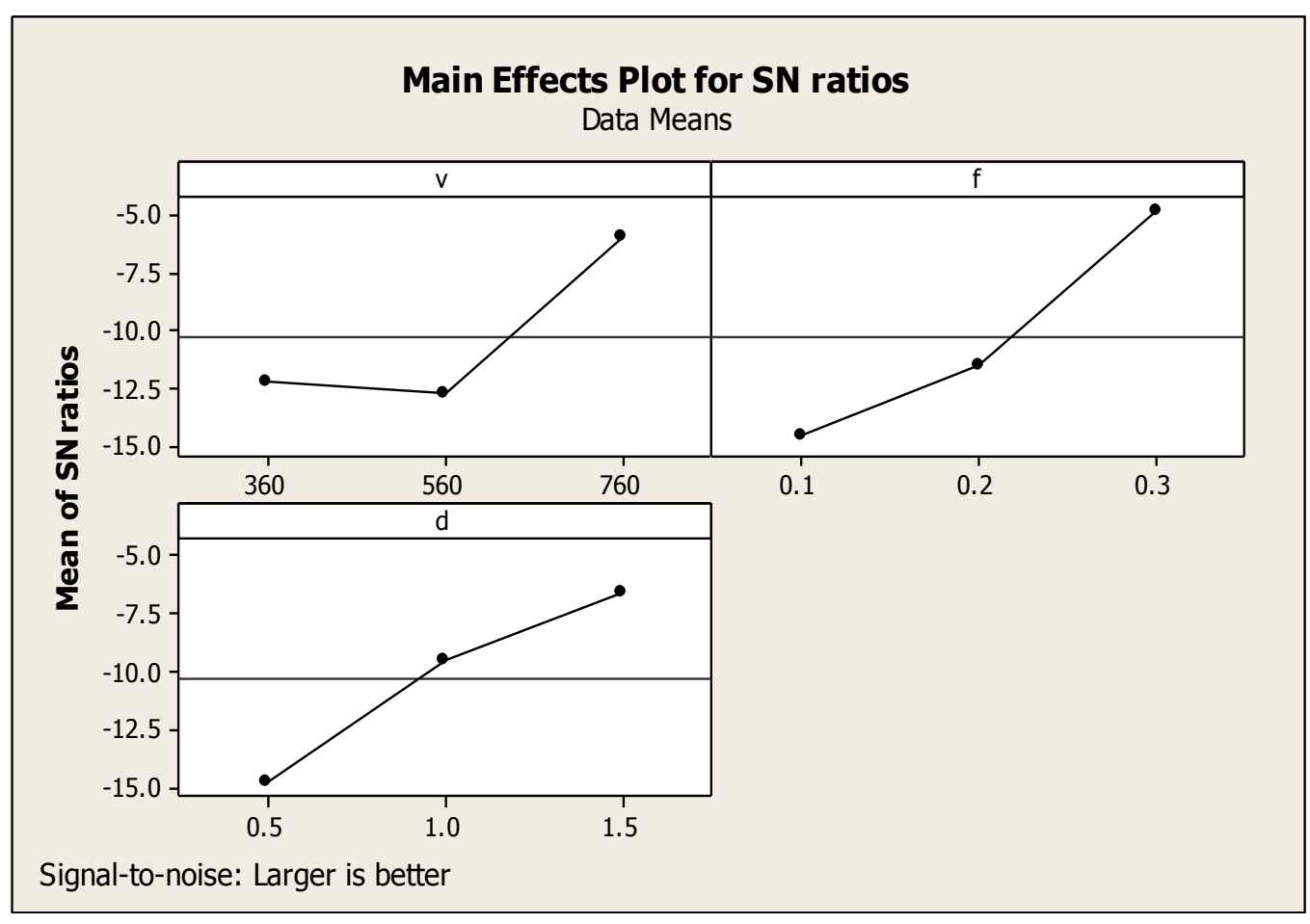

Figure 2. Main Effect Plot for S/N Ratios of $\mathrm{C}_{i}^{+}$ 


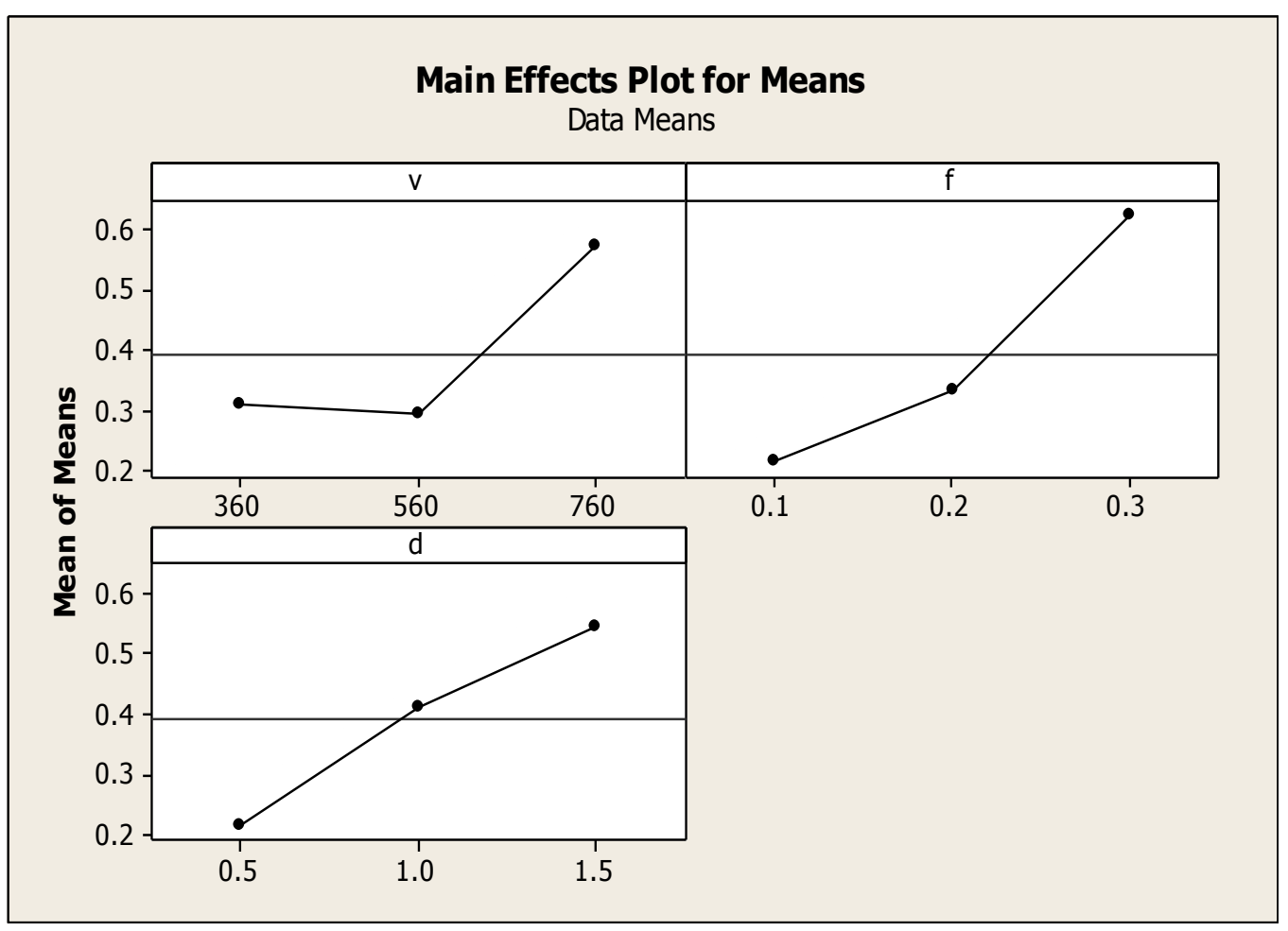

Figure 3. Main Effect Plot for Mean of Means of $\mathrm{C}_{i}^{+}$

Analysis of variance (ANOVA) has been done to find the influence of cutting parameters on the Relative closeness coefficient $\left(\mathrm{C}_{\mathrm{i}}^{+}\right)$and the results were given in the Table 12. From the ANOVA results, it is clear that the feed is the high influencing parameter $(F=41.08)$ and Speed is the low influencing parameter $(F=22.55)$ for the relative closeness coefficient $\left(\mathrm{C}_{\mathrm{i}}^{+}\right)$. The residual plots for $\mathrm{C}_{\mathrm{i}}^{+}$were drawn and shown in the figure 4.The residual plots representing that all the residuals are following the normal distribution, constant variance and also they are not representing any regular pattern.

Table 12. ANOVA for $\mathrm{C}_{i}^{+}$

\begin{tabular}{|c|c|c|c|c|c|c|c|}
\hline Source & DF & Seq SS & Adj SS & Adj MS & F & P & Remarks \\
\hline v & 2 & 0.43603 & 0.43603 & 0.21802 & 22.55 & 0.000 & Significant \\
\hline f & 2 & 0.79438 & 0.79438 & 0.39719 & 41.08 & 0.000 & Significant \\
\hline $\mathrm{d}$ & 2 & 0.49864 & 0.49864 & 0.24932 & 25.78 & 0.000 & Significant \\
\hline Error & 20 & 0.19340 & 0.19340 & 0.00967 & & & \\
\hline Total & 26 & 1.92246 & & & & & \\
\hline
\end{tabular}

$S=0.0983357 ; R^{2}=89.94 \% ; R^{2}(\operatorname{Adj})=86.92 \%$ 


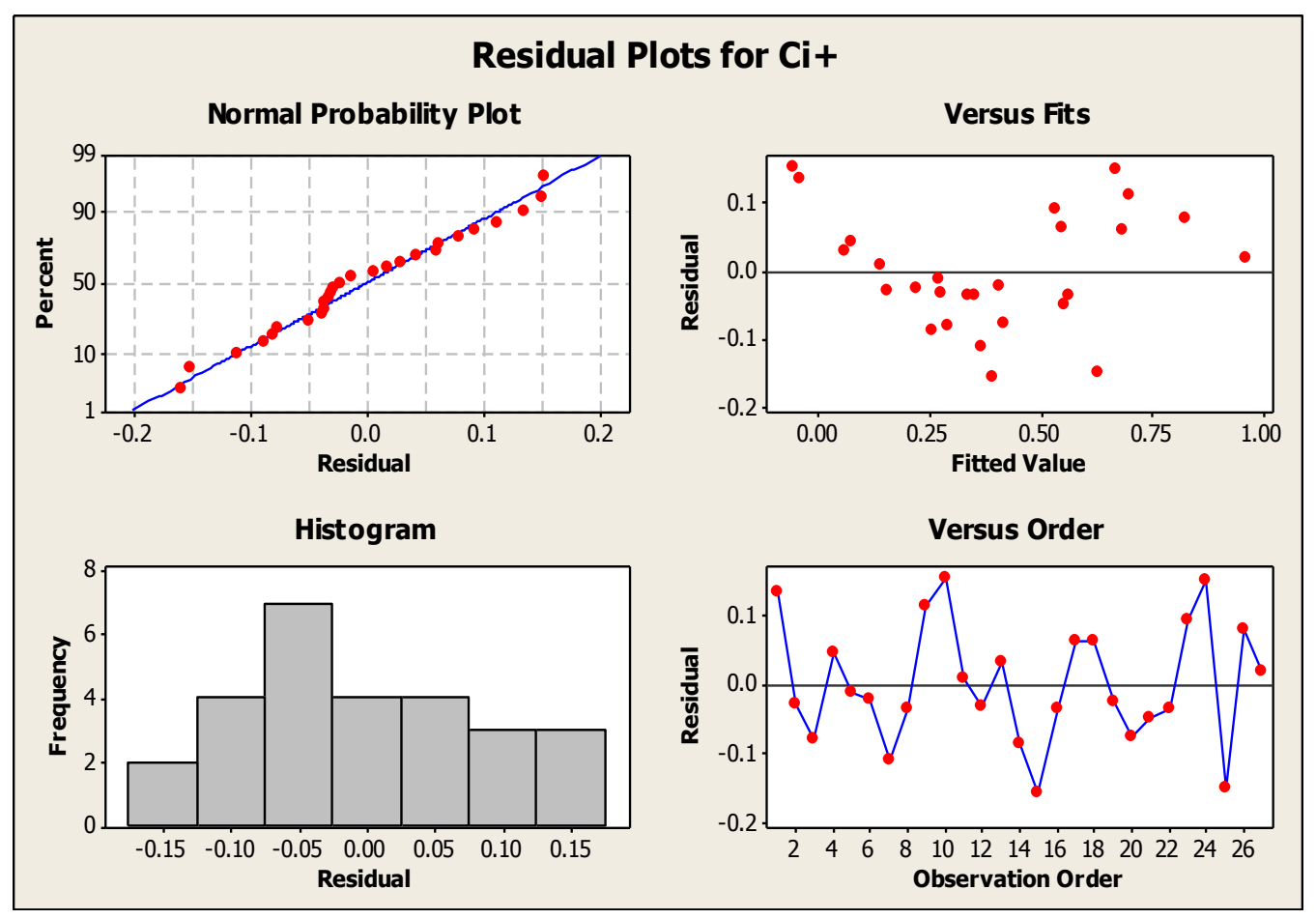

Figure 4. Residual Plots for $\mathrm{C}_{i}^{+}$

\section{Conclusions}

- From the TOPSIS the optimal combination of the multiple responses was found at the Speed: $760 \mathrm{rpm}$, Feed: $0.3 \mathrm{~mm} / \mathrm{rev}$ and depth of cut: $1.5 \mathrm{~mm}$.

- From the ANOVA results of the Relative closeness coefficient $\left(\mathrm{C}_{\mathrm{i}}^{+}\right)$, it is found that Feed is the high influencing parameter and speed is the low influencing parameter on the multiple-responses.

- From the residual plots for the relative closeness coefficient $\left(\mathrm{C}_{\mathrm{i}}^{+}\right)$, it is clear that the residual are following a normal distribution and they are not representing any regular pattern.

\section{References}

[1] H. Haleh and A. Hamidi, "A Fuzzy MCDM Model for Allocating Orders to Suppliers in a Supply Chain Under Uncertainity Over a Multi Period Time Horizon”, Expert Systems with Applications, vol. 38, no. 8, (2011), pp. 9076-9083.

[2] P. Kailiponi, "Analyzing Evacuation Decisions Using Multi-Attribute Utility Theory", Procedia Engineering, vol. 3, (2010), pp. 163-174.

[3] P. Konidari and D. Mavrakis, "A Multi-Criteria Evaluation Method for Climate Change Mitigation Policy Instruments", Energy Policy, vol. 35, no. 12, (2007), pp. 6235-6257.

[4] E. Loken, "Use of Multi-Criteria Decision Analysis Methods for Energy Planning Problems", Renewable and Sustainable Energy Reviews, vol. 11, no. 7, (2007), pp. 1584-1595.

[5] J. G. Limon, M. Arriaza and L. Riesgo, "An MCDM Analysis of Agricultural Risk Aversion”, European Journal of Operational Research, vol. 151, no. 3, (2003), pp. 569-585.

[6] S. H. Zanakis, A. Solomon, N. Wishart and S. Dublish, "Multi-Attribute Decision Making: A Simulation Comparison of Select Methods", European Journal of Operational Research, vol. 107, no. 3, (1998), pp. 507-529.

[7] M. A. Abo-Sinna and A. H. Amer, "Extensions of TOPSIS for Multi-Objective Large Scale Nonlinear Programming Problems", Applied Mathematics and Computation, vol. 162, (2005), pp. 243-256.

[8] G. R. Jahanshahloo, F. H. Lotfi and M. Lzadikhah, "An Algorithmic Method to Extend TOPSIS for Decision Making Problems with Interval Data", Applied Mathematics and Computations, (2005).

[9] M. Behzadian, S. Otaghsara, M. Yazdani and J. Ignatius, "A State-of-the-Art Survey of TOPSIS Applications”, Expert Systems with Applications, vol. 39, no. 17, (2012), pp. 13051-13069. 
[10] Y. Ic, "An Experimental Design Approach Using TOPSIS Method for the Selection of Computer-Integrated Manufacturing Technologies", Robotics and Computer-Integrated Manufacturing, vol. 28, no. 2, (2012), pp. 245-256.

[11] Y. Kim, E. Chung, S. Jun and S. Kim, "Prioritizing the Best Sites for Treated Wastewater In stream use in an Urban Water Shed Using Fuzzy TOPSIS", Resources, Conservation and Recycling, vol. 73, (2013), pp. 23-32.

[12] R. Simanaviciene and L. Ustinovichius, "Sensitivity Analysis for Multiple Criteria Decision Making Methods: TOPSIS and SAW", Procedia Social and Behavioural Sciences, vol. 2, (2010), pp. 7743-7744.

[13] K. L. Wen, T. C. Chang and M. L. You, "The Grey Entropy and its Application in Weighting Analysis", IEEE International Conference on Systems, Man and Cybernetics, vol. 2, (1998), pp. 1842-1844.

[14] S. Ding and Z. Shi, "Studies on Incident Pattern Recognition Based on Information Entropy", Journal of Information Science, vol. 31, no. 6, (2005).

[15] P. S. Rao, K. Ramji and B. Satyanarayana, "Effect of WEDM Conditions on Surface Roughness: A Parametric Optimisation Using Taguchi Method", International Journal of Advanced Engineering Sciences and Technologies, vol. 6, (2011), pp. 041-048.

[16] F. Han and J. Jiang, "Influence of machining parameters on surface roughness in finish cut of WEDM", The International Journal of Advanced Manufacturing Technology, vol. 34, no. 5-6, (2007), pp. 538-546.

[17] M. Durairaj, D. Sudharsun and N. Swamynathan, "Surface Roughness Optimization in Wire Cut EDM using Taguchi Method", Proceedings of the National Conference on Fascinating Advancements in Mechanical Engineering, (2013), pp.176.

[18] S. S. Chaudhari, S. S. Khedka and N. B. Borkar, "Optimization of Process Parameters Using Taguchi Method Approach with Minimum Quantity Lubrication for Turning", International Journal of Engineering Research and Applications, vol-1, no. 4, (2011), pp.1268.

[19] A. Vishal Parashar, J. L. Rehman, Bhagoria and Y.M Puri, "Investigation and Optimization of Surface for Wire Cut Electro Discharge Machining of SS 304 Using Taguchi Method", International Journal of Engineering, (2009), pp. 257-267.

[20] M. Nalbant, H. Gokkayya and G. Sur, "Application of Taguchi Method in the Optimization of Cutting for Surface Roughness in Turning”, Elsevier Journal, Measurement, vol. 44, (2007), pp. 1379-1385.

[21] S. Thamizhmanii, S. Saparudin and S. Hasan, "Analysis of Surface Roughness by Turning Process Using Taguchi Method", Journal of Achievements in Materials and Manufacturing, vol. 20, no. 1-2, (2007), pp. 503-506.

[22] M. KAladhar, K. Venkata Subbaiah and C. S. Rao, "Determination of Optimal Process During Turning of AISI 304 Austenitic Stainless Steel Using Taguchi Method and ANOVA", International Journal of Lean Thinking, vol. 3, no. 1, (2012).

[23] B. M. Gopala Swamy, B. Mondal and S. Ghosh, "Taguchi Method and ANOVA: An Approach for Optimization of Hard Machining While Machining Hardened Steel”, Journal of Scientific and Industrial Research, vol. 68, (2009), pp. 686-695. 